\section{Obituary Thomas P Detre}

Neuropsychopharmacology (20II) 36, 2783; doi: I0.1038/npp.201 I. I I0

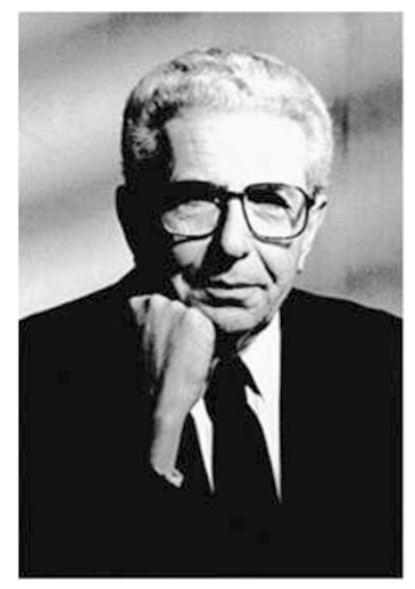

Thomas P Detre, a renowned psychiatrist, academic leader, health-care visionary, and a long-term member of the ACNP, died on Saturday, 9 October 2010, after a long illness at the age of 86 .

He was born in Budapest, Hungary, in 1924 and received his medical degree at the University of Rome. After coming to the United States in 1955, he joined the Department of Psychiatry at Yale in 1957. Between 1957 and 1973, he left an indelible mark at the Yale Medical School by establishing a new model for psychiatric care in which treatments were delivered in an integrated manner and the length of hospitalization was shortened dramatically. His creative approaches also provided a model for the treatment of mental and addictive disorders to move closer to that in other domains of medicine. His pioneering approach to relationships between clinical and research activities with academic medical centers was carried forward in his new position when in 1973 he left Yale to become the Chair of the Department of Psychiatry at the University of Pittsburgh Medical Center.

Tom Detre proved to be a creative academic leader whose ambition, drive, and vision are credited with the transformation of, first, the Department of Psychiatry and, then, the entire medical center at the University of Pittsburgh to a position of international prominence.

After 1983, when he became Vice Chancellor of the University of Pittsburgh Medical Center, a dramatic increase in the variety of clinical and research activities within the entire medical center occurred. The combination of academic and clinical success vaulted UPMC to a position as one of the top 10 medical centers in the United States in terms of research funding.

Tom Detre was the recipient of many honors, including an honorary medical degree from Semelweiss University and a doctor of humane letters from Carnegie Mellon University. The University of Pittsburgh named the main building of the Western Psychiatric Institute and Clinic Thomas Detre Hall. He also served as a member of the Institute of Medicine of the National Academy of Sciences.

Many stories abound about his organization and creative talent. He had the wonderful ability to say what was needed to be done, and then he gave people a very early sense of freedom and independence to do it, to get things done on their own. He was not a micromanager.

Dr Detre's role as a successful recruiting 'talent scout' in the 1970s coincided with the rise to greatness of the city's professional football team. When both the football team and the Department of Psychiatry were doing well, we were frequently called the 'Pittsburgh Stealers' for snapping up talent from top schools, including nearly 30 colleagues from Yale. Tom was the coach of the 'Pittsburgh Stealers.'

Detre also was a terrific organizer, pulling together researchers from different disciplines and programs. What he provided for me and hundreds of other people was a wonderful role model of what a physician could do at the interface between psychiatry and medicine. In that sense, he was my role model. Whatever skill set I now have in dealing with researchers derived from watching him and experiencing him, going back to when he was my mentor as a young student in New Haven. Tom created a culture of collaboration, a pervasive attitude that welcomed men and women, junior faculty, as well as established MDs and PhDs.

Tom Detre loved the ACNP. As a member, council member, President, and Chair of numerous committees, he served the College well for almost 35 years. He played a critical role in the ACNP during this period and provided important advice to countless members over the years. The ACNP will miss him, as will his many colleagues at Pittsburgh, New Haven, and around the world.

$$
\begin{array}{r}
\text { David J Kupfer }{ }^{1} \\
{ }^{1} \text { Department of Psychiatry, } \\
\text { University of Pittsburgh School of Medicine, } \\
\text { Western Psychiatric Institute and Clinic, } \\
\text { Pittsburgh, PA, USA } \\
\text { E-mail: kupferdj@upmc.edu }
\end{array}
$$

